\title{
The influence of various aspects of enjoyment on participation in leisure time physical activity
}

\author{
Melinda J. Craike \\ Deakin University, Australia \\ Raymond Hibins, Graham Cuskelly \\ Griffith University, Australia
}

\begin{abstract}
This study examines the direct and indirect influence of various aspects of enjoyment, including activity enjoyment, enjoyment conceptualised as physical/environmental, and enjoyment conceptualised as social interaction, on regular participation in leisure-time physical activity (LTPA). The study was cross-sectional and used self-report questionnaires to collect data from a random sample of 250 people aged 19-87 years living in an Australian city. Questionnaires included demographic items and scales to measure enjoyment of LTPA, prioritisation of LTPA and regularity of participation in LTPA. The findings suggest that the influence of enjoyment on participation in LTPA is complex. Aspects of enjoyment have varying levels of influence on participation in LTPA and this influence is indirect through preference for LTPA, life priority of LTPA and making time for LTPA. Policies, programs and strategies by government and practitioners that aim to increase participation in LTPA should primarily aim to enhance activity enjoyment, rather than focusing on other aspects of participation. Theoretically, this study suggests that enjoyment is a multidimensional concept and that enjoyment is a part of a larger decision-making process influencing participation in LTPA.
\end{abstract}

Keywords: physical activity, exercise, enjoyment, preference, priority, barriers

\section{Introduction}

There is an extensive body of empirical evidence which demonstrates the physical and psychological health benefits of physical activity (e.g., Stephenson, Bauman, Armstrong, Smith, \& Bellew, 2000; U.S. Department of Health \& Human Services [USDHHS], 1996). Despite an awareness of these benefits, half the Australian adult population does not participate in sufficient levels of physical activity to achieve a health advantage (see, e.g., Bauman, Ford \& Armstrong, 2001). The elevation of levels of physical activity is best achieved through participation in leisure time physical activity (LTPA). LTPA is easier to promote than other types of physical activity and people can modify their LTPA when they may have less control over their levels of occupational and domestic physical activity (Ainsworth, Bassett, Strath, Swatz, O'Brien, Thompson et al., 2000). Leisure-time physi- 
cal activity refers to recreational and sport physical activity, including a range of activities conducted specifically for enjoyment, social, competitive or fitness purposes, performed in leisure or discretionary time (Armstrong, Bauman \& Davies, 2000). Regularity of participation is required to achieve health benefits. Thus, acquisition of benefits through LTPA requires a significant leisure lifestyle modification (Tsai, 2002, 2005). It is important to understand significant determinants of regular LTPA to develop strategies that will enhance people's participation (Ajzen, 1985).

\section{Enjoyment of LTPA}

Enjoyment has been shown to be a strong determinant of participation in, and adherence to, LTPA (Henderson, Glancy, \& Little, 1999; Kimiecik \& Harris, 1996; Salmon, Owen, Crawford, Bauman, \& Sallis, 2003; Wankel, 1985, 1993). There has, however, been little research that examines the process through which enjoyment influences participation in LTPA. Most research has assumed that the influence of enjoyment is direct but our understanding of the process through which enjoyment predicts participation in LTPA is limited.

Enjoyment is generally conceptualised as a single dimensional construct. Some research, however, suggests that enjoyment might be multidimensional in nature (e.g., Gauvin, 1990; Kendzierski \& DeCarlo, 1991). An external focus, such as focusing on the environment in which the activity occurs or listening to music, can improve LTPA performance and, as part of multifaceted intervention, can enhance adherence (e.g., Martin, Dubbert, Katell, Thompson, Raczynski, Lake et al., 1984; Masters \& Lambert, 1989; Padgett \& Hill, 1989; Pennebaker \& Lightner, 1980). Anecdotal evidence suggests that people also use strategies such as listening to music while participating in LTPA to increase their level of enjoyment and improve their performance (Kendzierski \& DeCarlo, 1991). Focusing on external aspects of the experience may make LTPA more enjoyable either because these aspects distract the individual from boredom or physical discomfort or because they add a pleasurable component to the experience (Kendzierski \& DeCarlo, 1991).

A qualitative study by Gauvin (1990) found that people who participated in regular LTPA were drawn to the activity for the activity itself, whereas those who had dropped out of participating as well as sedentary individuals reported that they liked a wide variety of aspects of participation in LTPA, including social aspects and situational aspects, but often excluding the activity itself (Gauvin, 1990). Taken collectively, these findings indicate that it might be useful to examine the influence, not only enjoyment of LTPA itself, but also the influence of more specific types of enjoyment, such as enjoyment of the social interaction and environments that accompany the physical activity.

There is limited research on the influence of enjoyment when it is dependent on social factors and/or environments where it takes place. From this perspective, the individual's enjoyment of LTPA is dependent on factors such as social interactions and physical surroundings. This 'external' enjoyment is different to enjoyment that results from participating in the activity itself.

External factors, such as environment and social factors, may be used to 'cope' with participation in LTPA. Thus, if people do not enjoy participating in LTPA, they might rely on other types of enjoyment to enhance their overall perception of the experience. Social and environmental influences on participation in LTPA have been discussed and their positive influence has been identified (Gabriele, Walker, Gill, Harber, \& Fisher, 2005; Giles-Corti, \& Donovan, 2003; McGinna, Evensonb, Herringc, Huston, 2007). For example, McGinna et al (2007) showed that perceptions of the natural environment were associated with physical activity and concluded that researchers should consider perceptions of the natural environ- 
ment when developing physical activity interventions. Previous research has not, however, examined the influence of environmental influences and social interaction when individuals rely on these factors to make their experience a more enjoyable one.

The distinction between enjoyment of the activity itself and enjoyment that is dependent on factors external to the activity shares similarities with Deci and Ryan's (1985, 1991; Ryan \& Deci, 2000) self-determination theory. According to this theory, motivational types form a continuum ranging from intrinsic motivation to extrinsic motivation (Deci \& Ryan, 1985, 1991; Ryan \& Deci, 2000). Activity enjoyment shares similarities with intrinsic motivation. In fact, some previous work has operationalised intrinsic motivation as enjoyment (e.g., Li, 1999; McAuley, Duncan, \& Tammen, 1989; Mullan, Markland, \& Ingledew, 1997).

A number of studies suggest that in the context of sport and organised physical activity, intrinsic motivation and the more intrinsically regulated forms of behaviour regulation tend to be associated with positive outcomes such as effort, intentions and later stages of change (e.g., Pelletier, Fortier, Vallerand, Tuson, Briere, \& Blais, 1995; Wilson, Rogers, \& Fraser, 2002a and b). In contrast, extrinsic types of behaviour regulation tend to be associated with more negative outcomes (e.g., Pelletier et al., 1995; Thogersen-Ntoumani \& Ntoumanis, 2006). Enjoyment dependent on social and environmental factors shares similarities with external forms of behaviour regulation. Thus, it could be expected that activity enjoyment will have a positive influence on participation in LTPA, while enjoyment characterised by social and environmental factors will have a less positive, perhaps even negative, influence on participation.

Knowledge of the influence of various aspects of enjoyment has theoretical and practical implications for the study of the determinants of regular participation in LTPA. Theoretical implications include an understanding of the nature of the concept of enjoyment and the process through which enjoyment has an influence on behaviour. Practical implications include assisting in the design of programs and interventions to enhance frequency of participation in LTPA and helping to focus strategies.

In summary, enjoyment has been shown to be an important determinant of participation in leisure-time physical activity. Evidence suggests that elements such as social factors and environmental factors may influence the individual's perceptions of enjoyment. The behavioural outcomes of enjoyment that arise when enjoyment is dependent on external sources compared to enjoyment of the activity itself have not been examined. The interaction, and relative importance, of enjoyment compared to other determinants has not received a great deal of research attention and there is little evidence of the ways in which enjoyment influences regularity of participation in LTPA.

One way that enjoyment might influence participation in LTPA is through a decisionmaking process that includes the formation of preferences, prioritisation and time allocation. Craike (2007) proposed that regular participation in LTPA is not characterised by a simple choice as it involves deciding between a range of competing leisure behaviours and life priorities. Craike found that forming a preference for LTPA does not necessarily mean that the individual will engage regularly in the activity. People must also prioritise LTPA and have the skills to allocate time to it if they are to become regular participants. From this perspective, individuals are seen as actively constructing their use of leisure through a decision-making process that involves the allocation of time to activities that are of high life importance. The present study seeks to extend work on the decision-making process involved in regular participation in LTPA work by testing the proposition that preference, priority and making time are proximal predictors of regular participation in LTPA that mediate the 
Figure 1. Proposed model: Relationship between enjoyment factors, preferences, life priority, making time and regularity of participation in LTPA

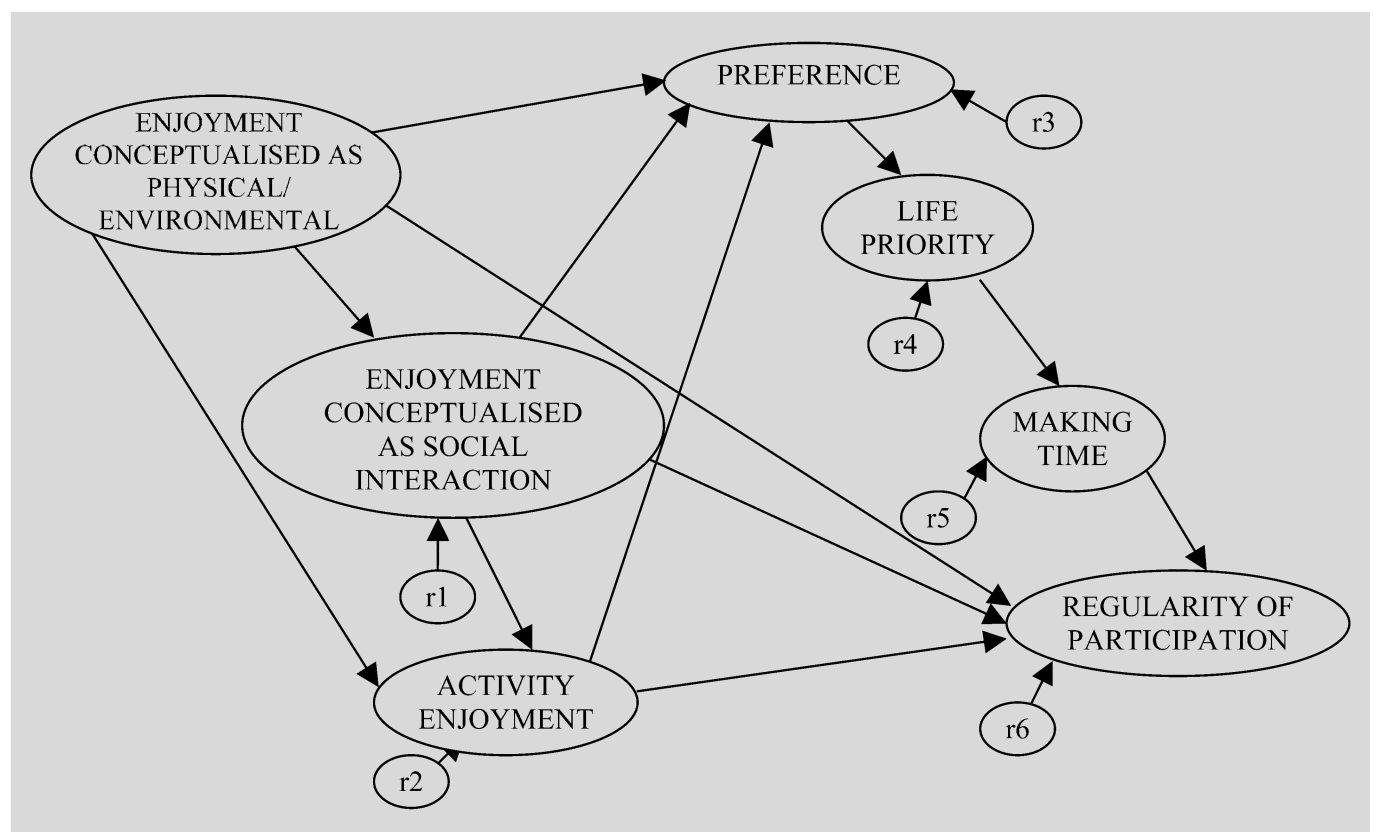

influence of enjoyment on regular participation in LTPA.

Enjoyment of LTPA was conceptualised as being a multidimensional construct that is an affective response to LTPA. The three dimensions are: (1) activity enjoyment; (2) enjoyment conceptualised as physical/environmental; and (3) enjoyment conceptualised as social interaction. Activity enjoyment is defined as feeling pleasure and happiness that arises from participation in the actual leisure-time physical activity. Enjoyment conceptualised as physical/environmental describes enjoyment of LTPA that is dependent on the physical location and environment where it occurs. The focus here is on enjoyment of leisure-time physical activity because of the location where it takes place, rather than the activity itself. Enjoyment conceptualised as social interaction describes enjoyment derived from the social interaction that occurs as a result of participation in leisure-time physical activity. The focus here is on enjoying the activity because it means being with other people; the source of enjoyment is not the activity itself.
This study broadens the concept of enjoyment of LTPA by examining the influence of three dimensions of enjoyment on participation in LTPA. It was expected that the three enjoyment dimensions would influence regular participation in LTPA through their influence on preference, priority and time. It was also expected that activity enjoyment would have a stronger influence on preference than enjoyment conceptualised as physical/environmental or enjoyment conceptualised as social interaction. It is possible, however, that all the enjoyment dimensions influence regular participation in LTPA directly and this effect was also assessed (See Figure 1).

\section{Method}

\section{Participants and procedure}

The population from which the sample was selected consisted of individuals aged 18 years or over living independently. A sequential selection method was adopted to select 729 potential participants from the State Electoral Division role of an Australian city. 
Three sets of the questionnaires were mailed to enhance the return rate from potential participants (Dillman, 2000). A cover letter explained the purpose and importance of the research, the value and confidentiality of responses and the voluntary nature of participation. The cover letter also contained the contact information of the researchers. Reply-paid envelopes were included. Two hundred and fifty valid questionnaires were returned, after accounting for 59 people who could not be contacted, giving a response rate of $37.3 \%$. Ethics approval for this research project was gained from Griffith University prior to collecting data.

There were 132 females (53.2\%) and 116 males $(46.8 \%)$ in the sample $(n=248)$. The age of participants ranged from 19 to 87 years, with a mean age of 48 years $(S D=18)$. The highest level of education achieved for almost half of participants (42.8\%) was high school (7.6\% indicated that they did not complete high school). Post secondary qualifications included: TAFE (Technical and Further Education)/Technical qualifications (17.2\%), bachelor degree (14.8\%), postgraduate studies (11.6\%), and associate/ undergraduate diploma (6.0\%). Over threequarters of the sample were born in Australia (77.5\%).

\section{Instruments}

Items were developed for this study based on previous studies and a qualitative study conducted as the first stage of this research (Craike, 2005). Prior to the main study, a pilot study was conducted to refine the questionnaire. Focus group discussions were held with a group of university students to assess the ease of response, the clarity of the item wording and instructions. As well as discussions with survey respondents, a small expert panel of academics in the area of leisure research was asked to complete a survey and feedback was sought. As a result of the pilot study, adjustments were made to some items and questionnaire instructions. For example, changes were made to the way in which regular participation in leisure-time physical activity was measured to address concerns about the clarity of items. Meanings of terms such as 'physical activity' and the length of time that defines a physical activity 'session', were more clearly defined in the questionnaire and the measure was reconstructed to make recall of physical activity sessions easier. Furthermore, perceptual indicators were included to supplement the behavioural measure of participation in regular leisuretime physical activity. Changes to other sections of the questionnaire included rewording of some items and/or reduction in the number of items because many respondents felt the questionnaire was repetitive.

\section{Enjoyment of LTPA}

Enjoyment of LTPA was measured as a multidimensional construct. Four items measured activity enjoyment including; 'I enjoy being physically active', 'Physical activity is boring' (negative), 'Participating in physical activity puts me in a good mood' and 'Physical activity is good fun'. Three items measured enjoyment conceptualised as physical/environmental, including; 'I enjoy physical activity more when it takes place in attractive locations', 'The place where I participate in physical activity generally influences how much I enjoy it' and 'Nice surroundings help me to forget I'm being physically active'. Six items measured enjoyment dependent on social interaction, including; 'Physical activity is more fun with lots of people', 'For me the social part of participation in physical activity is more enjoyable than the activity itself', 'Participating with other people makes physical activity more of a social event and less like a chore', 'It is easier to stick to physical activity when you have someone to participate with', 'I usually participate in physical activity because it means I can be with friends' and 'I like participating in physical activity by myself' (negative). All enjoyment items were measured on a 5-point Liker-type scale ranging from 'strongly agree' (5) to 'strongly disagree' (1).

\section{Prioritisation of LTPA}

This was considered a multidimensional construct that included preference for LTPA, 
LTPA as a life priority and making time for LTPA $^{1}$. This section briefly outlines the conceptualisation and measurement of prioritisation of LTPA. More detail about the measurement can be found in Craike (2007). Four items measured preference for LTPA, including; 'I get more pleasure out of doing other things in my spare time than physical activity' (reverse coded), 'I get satisfaction from participating in physical activity but I'd rather be doing something else'(reverse coded), 'During my spare time I like to relax rather than exerting myself in physical activity' (reverse coded), and 'If I have a couple of spare hours I'd rather do some sort of physical activity than other things'. Two items measured LTPA as a life priority, including; 'At this time in my life I am putting off becoming physically active' (negative) and 'Being physically active is not a high priority for me at the moment' (negative). Three items measured making time for LTPA, including; 'I can always find time to be physically active', 'I find that I haven't got enough time in the day to fit in physical activity' (negative), and 'I don't have any free time to participate in physical activity' (negative).

All prioritisation items were measured on a 5-point Likert-type scale ranging from 'strongly agree' (5) to 'strongly disagree' (1). Negative items were reverse coded to reflect a high prioritisation of LTPA.

\section{Regular participation in LTPA}

Participation in LTPA was measured using one behavioural recall and two perceptual indicators. A mix of behavioural recall and perceptual indicators allowed for triangulation and provided a measure of regular participation in LTPA that was more robust than a behavioural measure alone. In this study, regular participation in LTPA refers to partici-

1 For simplicity, the following abbreviations are sometimes used throughout the paper: 'Preference for LTPA' is replaced by 'preference'; 'making time for LTPA' is replaced by 'making time', 'LTPA as a life priority' is replaced by 'life priority', and 'regular participation in LTPA' is replaced with 'regularity of participation'. pation in at least three sessions of LTPA per week.

To measure the behavioural aspect of regular participation in LTPA, this study adapted a measure developed and used by Tsai (2002, 2005). This measure assessed participation in leisure-time physical activities over the previous four weeks. First, respondents were asked, "In the past 4 weeks, have you participated in any physical activity that has lasted for at least 20 minutes at a time?" Those who answered 'yes' to this question were asked to nominate up to three physical activities in which they had participated during the previous four weeks. For each of the three activities they listed, participants were asked to recall the number of sessions for each activity.

This behavioural indicator of the regularity of participation in LTPA was calculated by assessing the number of weeks out of the previous four that respondents had participated in LTPA for at least three sessions. Therefore, scores ranged from zero (indicating that the respondent had not been physically active for three or more sessions over any of the past four weeks) to four (indicating that the respondent had been physically active for at least three sessions per week in each of the past four weeks).

Two indicators were used to measure the perceptual aspect of regular participation in LTPA. One perceptual indicator of regularity of participation in LTPA asked respondents to rate - on a 5-point scale, ranging from 'not at all' (1) to 'very regularly'(5) - how regularly they had participated in physical activity over the past four weeks. The second perceptual indicator measured respondents' perceptions of the regularity of their LTPA compared to that of other people. Respondents were asked to rate (on a 5-point scale ranging from 'much less regularly' (1) to 'much more regularly' (5)), how regularly they had participated in physical activity over the past four weeks, compared to other people of their age and sex. 


\section{Statistical analysis}

Initial data treatment and screening processes adhered to the recommendations provided by Tabachnick and Fidell (2007). After undertaking preliminary analysis to ensure that the values to be estimated were missing randomly, missing data were replaced using full information maximum likelihood estimation (Arbuckle, 1996; Enders \& Bandalos, 2001). Although there was some non-normality inherent in the data, maximum likelihood has been shown to be robust to moderate violation of the normality assumption (Anderson \& Gerbing, 1988; Hu, Bentler, \& Kano, 1992).

Structural equation modelling (SEM), using AMOS version 4, was the main type of data analysis used in this study. A two-stage analysis procedure was adopted whereby the measurement instruments were tested and refined prior to assessing the structural model (Anderson \& Gerbing, 1988). Confirmatory factor analysis (CFA) was used to test the factorial composition and structure of the factor indicators in the measurement model.

Examination of the correlation between factors in the models to determine whether discriminant validity was adequate $(<0.90)$, used standardised residuals, factor loadings, and modification indices to guide the modification of the measurement models. The process of model refinement for the structural model involved deleting all insignificant paths sequentially until all insignificant paths had been removed. After this, modification indices were examined to assess if any additional paths should be added to the model and paths were only added if they could be justified based on theory or evidence. Factors that did not retain an influence on regular participation in LTPA (either directly or indirectly) were removed from the model. This step ensured the model was parsimonious. The level of significance adopted in this study was $p=<.01$ (critical ratio $=>3.29$ ).

It is recommended that the evaluation of model fit in SEM is based on multiple criteria (Bollen, 1990). Based on guidelines by $\mathrm{Hu}$ and Bentler (1998, 1999) and Marsh, Balla and McDonald (1988) the standardised root mean square residual (SRMR), root mean square error of approximation (RMSEA), Tucker-Lewis index (TLI) and likelihood-ratio chi-square statistic $\left(\chi^{2} / d f\right)$ were used to assess model fit in the present study. As recommended by other researchers (e.g., Byrne, 1998; Schumacker \& Lomax, 1996), TLI values greater than .90 were used to indicate acceptable model fit, values of up to .08 were considered acceptable for SRMR and RMSEA, and 3 to 1 or less was adopted for the likelihood-ratio chi-square statistic.

\section{Results}

Factor structure of the measurement models

The three-factor enjoyment of leisure-time physical activity measurement model, which was conceptualised as having the factors activity enjoyment, enjoyment conceptualised as physical/environmental, and enjoyment conceptualised as social interaction, did not fit the data $\left(\chi^{2}=232.96 ; d f=62\right.$; $\chi^{2} / d f=3.78$; RMSEA $=.105 ;$ SRMR $=.111$; $\mathrm{TLI}=.812)$.

Sequential deletion of problematic indicators and the addition of an error covariance enhanced the fit of model. A modified threefactor model was tested after removing one indicator of activity enjoyment, three indicators of enjoyment conceptualised as social interaction and an error covariance between two of the enjoyment items $(r=.36)$. These items were 'I enjoy being physically active' and 'Physical activity is boring' (negative). It is possible that these items also measure the stimulating aspect of physical activity as an escape from boredom and this may explain the correlation between error covariances. The final three-factor model with three indicators of activity enjoyment, and three indicators of enjoyment conceptualised as social interaction and three indicators of enjoyment conceptualised as physical/environmental was a good fit for the data $\left(\chi^{2}=53.79\right.$; $d f=23 ; \chi^{2} / d f=2.34 ;$ RMSEA $=.073$; $\mathrm{SRMR}=.067 ; \mathrm{TLI}=.931$ ). 
The correlations between the factors in this model were low to moderate (ranging from $r=.26$ to .56). These correlations indicated that the three factors measured somewhat different aspects of enjoyment of leisure-time physical activity. The averages for the enjoyment factors were: activity enjoyment $(M=3.76, S D$. $=0.69, n=250)$; enjoyment conceptualised as physical/environmental, $(M=3.35, S D$. $=0.80, n=250)$; and enjoyment conceptualised as social interaction $(M=3.36, S D$. $=0.77, n=250)$. Generally, respondents reported a higher level of enjoyment of the physical activity itself than enjoyment conceptualised as social interaction or enjoyment conceptualised as physical/environmental.

Prioritisation of LTPA comprised three factors - preference, life priority and making time. The original three-factor model did not fit the data $\left(\chi^{2}=107.20 ; d f=24\right.$; $\chi^{2} / d f=4.47 ;$ RMSEA = .118; SRMR = .077; $\mathrm{TLI}=.854)$. Model modification included the deletion of one indicator from the making time factor that had a low factor loading and the inclusion of two error covariances between preference indicators. The first added error covariance was between preference indicators one and two $(r=.27)$ and the second was between indicators one and four $(r=.32)$. Items one and two were' 'I get more pleasure out of doing other things in my spare time than physical activity' (reverse coded) and 'I get satisfaction from participating in physical activity but I'd rather be doing something else' (reverse coded), respectively. These indicators refer to 'getting' something from participation in various types of leisure and therefore may also be measuring perceived benefits of various types of leisure. Items one and four were 'I get more pleasure out of doing other things in my spare time than physical activity' (reverse coded) and 'If I have a couple of spare hours I'd rather do some sort of physical activity than other things'. Both refer to preference for 'other things' (rather than more specific activities such as relaxation) and thus may be measuring preference for a broader range of other leisure.
This modified three-factor measurement model was a reasonable-to-good fit $\left(\chi^{2}\right.$, $d f=37.46,15 ; \chi^{2} / d f=2.50 ;$ RMSEA $=$ $.078 ;$ SRMR $=.040 ; \mathrm{TLI}=.941)$. The correlations between each of the three factors were moderate to high. The highest correlation was between preference and level of life priority $(r=.86)$, followed by the correlation between making time and level of life priority $(r=.77)$ and making time and preference $(r=.67)$.

The averages for the priority factors were: preference $(M=3.13, S D$. $=0.76$, $n=249)$; life priority $(M=3.45, S D .=0.98$, $n=250)$; making time $(M=3.27, S D=$ $0.85, n=250)$. The average scores suggested that respondents felt that leisure-time physical activity was a reasonably high priority.

The measurement validity of the indicators of regular participation in LTPA was assessed in the structural model. The loadings of the three indicators were very high (.791 to .893), indicating the convergent validity of the measurements of regular participation in LTPA. Over three quarters (77.2\%, $n=250$ ) of respondents indicated that they had participated in at least one session of LTPA that had lasted for at least 20 minutes in the previous four weeks. Just over half $(52.8 \%)$ participated for at least three, 20-minute, sessions over the previous four weeks. On average, respondents participated in at least three 20-minute sessions in just over two of the previous four weeks $(M=2.37, S D=1.868$, $n=250$ ). On average, respondents felt that they had participated between slightly irregularly (3) and fairly regularly $(4 ; M=3.55$, $S D=1.31, n=249$ ) in physical activity over the past four weeks. Respondents felt that their regularity of participation in physical activity was between the same (3) and slightly more regularly $(4 ; M=3.23, S D$. $=1.29$, $n=242$ ) than other people of their age and sex. The mean scores and standard deviations for each of the individual items included in the final measurement models can be seen in Tables 1, 2 and 3. 
Table 1. Descriptive statistics for prioritisation of LTPA

\begin{tabular}{lccccc}
\hline \multicolumn{1}{c}{ Item } & $\mathbf{n}$ & Min. & Max. & Mean & S.D \\
\hline Preference 1 $^{\wedge}$ & 250 & 1 & 5 & 3.06 & 0.947 \\
Preference2 $^{\wedge}$ & 250 & 1 & 5 & 3.35 & 0.967 \\
Preference3 $^{\wedge}$ & 250 & 1 & 5 & 3.11 & 1.020 \\
Preference4 $^{\wedge}$ & 249 & 1 & 5 & 3.00 & 0.969 \\
Priorityl $^{\wedge}$ & 249 & 1 & 5 & 3.54 & 1.074 \\
Priority2 $^{\wedge}$ & 249 & 1 & 5 & 3.37 & 1.092 \\
Time2 $^{\wedge}$ & 250 & 1 & 5 & 3.07 & 0.979 \\
Time3 $^{\wedge}$ & 250 & 1 & 5 & 3.60 & 0.974 \\
\hline
\end{tabular}

$\hat{\wedge}=$ Item reverse coded

Table 2. Descriptive statistics for enjoyment of LTPA

\begin{tabular}{lccccc}
\hline \multicolumn{1}{c}{ Item } & $\mathbf{n}$ & Min. & Max & Mean & SD \\
\hline Enjoy1 & 250 & 1 & 5 & 3.92 & 0.863 \\
Enjoy2^ & 250 & 1 & 5 & 3.83 & 0.937 \\
Enjoy3 & 250 & 1 & 5 & 3.74 & 0.830 \\
Enjoy4 & 250 & 1 & 5 & 3.80 & 0.868 \\
Social1 & 250 & 1 & 5 & 3.77 & 0.915 \\
Social2 & 250 & 1 & 5 & 3.08 & 0.970 \\
Social6 & 250 & 1 & 5 & 3.23 & 1.015 \\
Surr1 & 250 & 1 & 5 & 3.38 & 0.971 \\
Surr2 & 250 & 1 & 5 & 3.41 & 0.944 \\
Surr3 & 250 & 1 & 5 & 3.27 & 0.963 \\
\hline
\end{tabular}

$\hat{\imath}=$ Item reverse coded

Table 3. Descriptive statistics for regular participation in LTPA

\begin{tabular}{lccccc}
\hline \multicolumn{1}{c}{ Item } & $\mathbf{n}$ & Min. & Max. & Mean & SD \\
\hline Reg1 & 250 & 1 & 4 & 2.27 & 1.87 \\
Reg 2 & 249 & 1 & 5 & 3.55 & 1.31 \\
Reg3 & 242 & 1 & 5 & 3.23 & 1.29 \\
\hline
\end{tabular}

\section{Structural model}

It was predicted that the enjoyment factors would influence regular participation in LTPA through preference, life priority and making time. It is possible, however, that these factors influence regular participation in LTPA directly. Therefore, in the initial model, paths were also specified between the enjoyment factors and regular participation in LTPA (see Figure 1).

Although the original model was a good fit for the data $\left(\chi^{2}=323.91 ; d f=155\right.$; $\chi^{2} / \mathrm{df}=2.09 ; \mathrm{RMSEA}=.066 ;$ SRMR $=.075$; TLI = .905), insignificant paths were sequentially removed to make the model more parsimonious. Following the removal of insignificant paths, the fit of the model was $\operatorname{similar}\left(\chi^{2}=332.54 ; d f=160 ; \chi^{2} / d f=2.08\right.$; RMSEA $=.066$; SRMR $=.077 . \mathrm{TLI}=.906$, see Figure 2). The final model represented a moderate to good fit, as RMSEA, SRMR, and TLI were all within acceptable ranges. Furthermore, the upper and lower bound RMSEA estimates (lower bound $=.056$. and upper bound $=.076$ ) were close and within acceptable ranges which gives further confidence in the fit of the model. The predictor variables explained $62.0 \%$ of the variance in regularity of participation in LTPA.

To identify any potential under-estimation of standard errors from using the maximum likelihood estimation method with items that were not normally distributed, robust statistics were employed using bootstrap estimation methods (Efron \& Tibshirani, 1993). The results of the comparison between the bootstrapped estimates and the empirical estimates showed that all significant paths (at the $p=<.01$ level) were still significant in the bootstrapping results and biases were very small, ranging from no bias to a maximum of $0.20 \%$ difference. These results demonstrated that the results from using maximum likelihood estimation upon which the models were interpreted, were robust. The findings of the structural testing support the proposition that enjoyment factors have varying levels of influence on regular participation in LTPA and influence regular participation through their effect on preference, life priority and making time.

\section{Conclusions and limitations}

All three types of enjoyment influenced participation in LTPA indirectly through pref- 
Figure 2. Final model

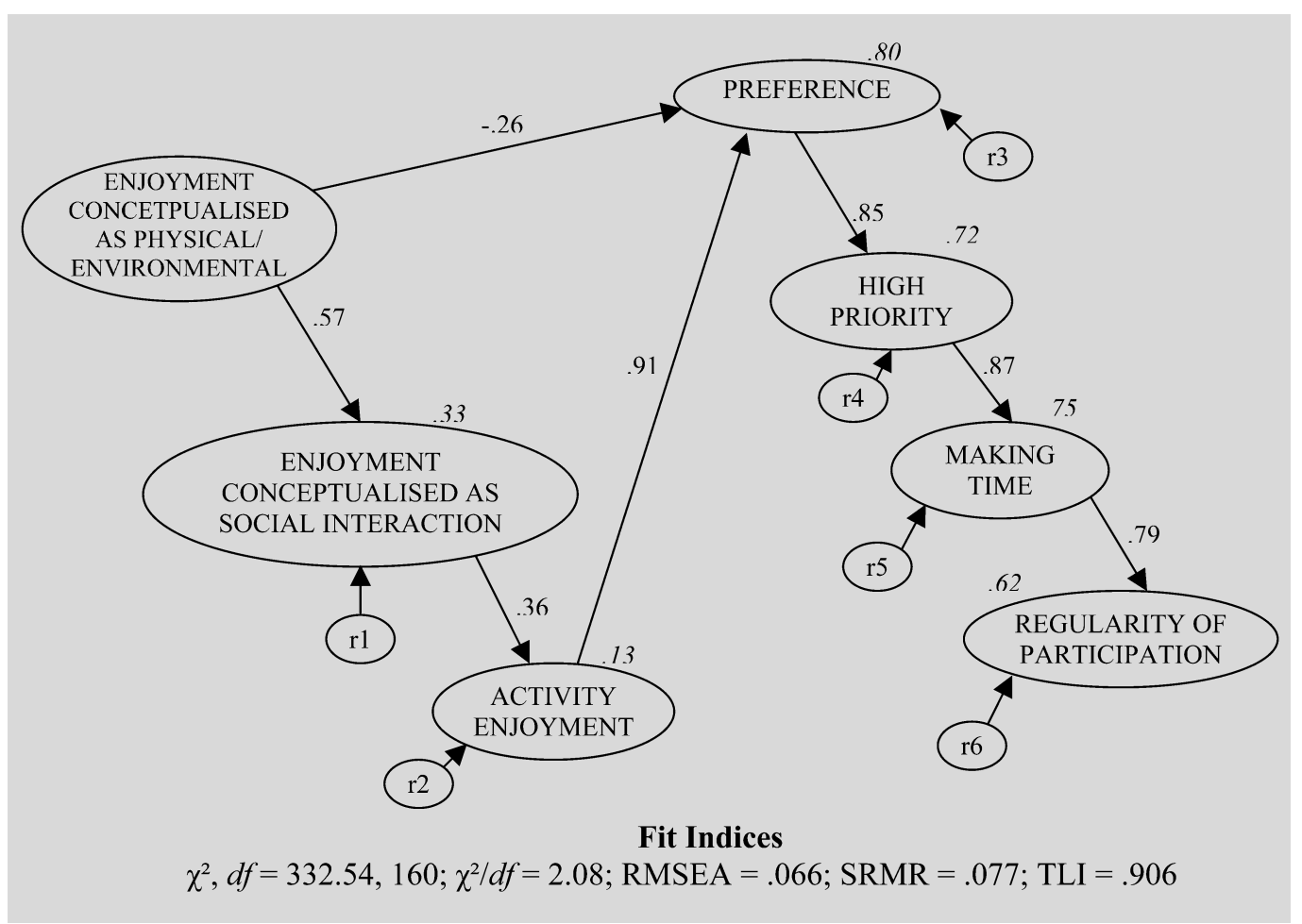

erence for leisure-time physical activity, rather than directly and there was diversity in the strength of the contribution of each type of enjoyment. Activity enjoyment influenced regular participation in leisure-time physical activity through its positive effect on preference. Thus, people who enjoyed leisure-time physical activity tended to develop preferences for it.

Enjoyment conceptualised as physical/environmental predicted regular participation in two ways. First, it had an indirect positive influence through enjoyment dependent on social interactions and consequently, activity enjoyment. That is, people who enjoyed participating in leisure-time physical activity when it took place in attractive environments were also those who were more likely to enjoy participating due to the social aspects of participation and consequently, enjoy the activity more. Second, enjoyment conceptualised as physical/environmental influenced leisure- time physical activity indirectly through its negative influence on preference for leisuretime physical activity. That is, people who enjoyed the surroundings where they were physically active were those who expressed a lower preference for LTPA.

Enjoyment conceptualised as social interaction predicted preference for leisure-time physical activity through its positive influence on activity enjoyment and subsequently, preference for leisure-time physical activity. Thus, people who enjoyed participating in leisure-time physical activity because of the social interactions of the experience, tended to enjoy the activity more.

Enjoyment conceptualised as physical/environmental positively, but indirectly, influenced activity enjoyment through enjoyment conceptualised as social interaction, which in turn positively influenced activity enjoyment. Thus, this study supports previous findings 
that enjoyment of external factors can enhance activity enjoyment. However, it should be noted that the associations between the enjoyment factors were moderate to weak, suggesting that they differ conceptually. People may use strategies such as concentrating on elements of the external environment while participating, participating with friends or listening to music, to cope with the boring nature of some LTPA and the physical discomfort that physical activity can cause. Also, previous research has shown that external elements such as the location of the activity, listening to music and social factors positively influence enjoyment, endurance, participation and adherence (Bauman, Smith, Stoker, Bellow, \& Booth, 1999; Kendzierski \& DeCarlo, 1991; Martin et al., 1984; Masters \& Lambert, 1989; Pennebaker \& Lightner, 1980).

Somewhat paradoxically, this study found that despite its positive association with activity enjoyment, enjoyment conceptualised as physical/environmental had a direct negative influence on preference for leisure-time physical activity. Gauvin (1990) found a similar negative association. In Gauvin's study, people who participated regularly in leisuretime physical activity were drawn to physical activity for the activities themselves, whereas those who had dropped out of participating as well as sedentary individuals reported that they liked a wide variety of aspects of participation in leisure-time physical activity including social situational aspects, but often excluding physical activity per se.

These relationships are consistent with the patterns found in studies that have used selfdetermination theory by demonstrating the positive influence of activity enjoyment and the less positive, and in some cases negative, influence of external forms of enjoyment (Pelletier et al., 1995; Thogersen-Ntoumani \& Ntoumanis, 2006; Wilson et al., 2002a and $b$ ). These findings are logical, considering that external regulation is somewhat similar in nature to externally referenced enjoyment of surroundings, and intrinsic motiva- tion is somewhat similar to internally referenced activity enjoyment.

The complex nature of the association between the various types of enjoyment found in this study and the potentially negative influence of externally referenced enjoyment (such as enjoyment conceptualised as physical/environmental) on preference and participation in leisure-time physical activity, requires further exploration. The relationship between the enjoyment factors and preference and participation could be examined longitudinally to understand the temporal relationship between enjoyment and participation. The cross-sectional nature of this study means that causality cannot be established. It may be that the relationship between enjoyment and participation in LTPA is cyclic, that is, enjoyment positively influences participation and as a person participates more, so they tend to enjoy their participation more.

The continuum of externally reference and internal enjoyment might be consistent with self-determination theory (Deci \& Ryan, 1985, 1991), whereby externally referenced enjoyment can become internalised and the individual begins to enjoy the physical activity for its own sake. This process may occur in stages as some people might start participating in LTPA and rely on the external factors (such as the physical environment or social interaction) to maintain an adequate level of enjoyment. With continual participation, however, their enjoyment might become more internalised and more closely aligned with the activity itself.

This study shows that enjoyment has an indirect, rather than a direct influence on LTPA, thus adding to theoretical understanding about the manner in which enjoyment influences participation in LTPA. This study also supports Crake's (2007) contention that preference, priority and making time are key proximal determinants of LTPA, and other factors, such as enjoyment, influence regular participation in LTPA indirectly through these factors. 
Prioritisation was thus a central determining factor of regular participation in LTPA. People develop leisure preferences from a range of leisure choices, form life priorities and allocate time to participate. These factors are part of a decision-making sequence. If people are to incorporate regular participation in LTPA into their lifestyle, they must first develop a preference for it, make it a priority in their life, and make time to participate.

Enjoyment is important when examining regular participation in LTPA because it is likely to be a significant link in the relationship between participation in LTPA and positive outcomes such as positive mental health and wellbeing (Wankel, 1993). Wankel (1993) suggested that an emphasis on enjoyment of LTPA may have significant positive outcomes in two ways. One is its importance to leisure-time physical activity adherence and the second is through countering stress and facilitating positive psychological health. Despite the general consensus that physical activity is associated with psychological benefits (e.g., USDHHS, 1996), the underlying mechanisms that mediate the psychological benefits of activity have not been specified. It is expected, however, that enjoyment of leisure-time physical activity plays an important role in this relationship (Wankel, 1993).

Practical implications of this research are that policies, programs and strategies by government and practitioners that aim to increase participation in LTPA should primarily aim to enhance activity enjoyment, rather than focusing on other aspects of participation. Research findings from a number of different theoretical perspectives have demonstrated that testing one's skills or competencies against relative task challenges influences level of enjoyment in the activity (Csikszentmihalyi, 1975, 1990; Deci, 1975; Deci \& Ryan, 1985; Iso-Ahola, 1980). This highlights the importance of leisure programmers and leaders ensuring that they are able to match the challenge of physical activities to the skill level of participants. Although it is important to enhance enjoyment of the activity experience, which includes settings and social interactions, it is vital that programmers' primary aim is to enhance enjoyment of the physical activity itself.

Craike (2007) suggested that due to the importance of preference, prioritization and time management, interventions to increase LTPA should focus on the time in people's lives when leisure preferences are formed and encourage people to prioritise LTPA and develop time management skills.

Limitations of this research should be taken into consideration when interpreting the findings of the study. These include the cross-sectional nature of the data, the use of a 4-week assessment of LTPA, the use of a self-reported measure of LTPA and self-selection bias. These limitations are inherent in survey research which recruits voluntary respondents via informed consent (Sallis \& Saelens, 2000).

The findings of this study indicate that it is important to examine enjoyment as a multidimensional construct and examine the predictors and outcomes of each component to more fully understand the relationship between enjoyment and regular participation in LTPA. Examination of the ways in which enjoyment might influence regularity of participation is important considering that research in this area is limited. This research represents an initial attempt to conceptualise enjoyment of LTPA as a multidimensional construct and to explain the mechanisms through which enjoyment influences participation in LTPA.

\section{REFERENCES}

Ainsworth, A., Bassett, D., Strath, S., Swatz, A., O'Brien, W., Thompson, R., et al. (2000). Comparison of three methods of measuring the time spent in physical activity. Medicine and Science in Sports and Exercise, 32, S457-S464.

Ajzen, I. (1985). From intentions to actions: A theory of planned behavior. In J. Kuhl, \& J. Beckman 
(Eds.), Action-control: From cognition to behavior (pp. 11-39). Heidelberg, Springer.

Anderson, J. C., \& Gerbing, D. W. (1988). Structural equation modelling in practice: A review and recommended two-step approach. Psychological Bulletin, 103, 411-423.

Arbuckle, J. L. (1996). Full information estimation in the presence of incomplete data. In G. A Marcoulides, \& R.E. Schumacker (Eds.), Advanced structural equation modelling (pp. 243-277). Mahwah, N.J: Lawrence Erlbaum Associates.

Armstrong, T., Bauman, A., \& Davies, J. (2000). Physical activity patterns of Australian adults. Results of the 1999 National Physical Activity Survey. Canberra, Australia: Australian Institute of Health and Welfare.

Craike, M.J. (2005). An exploratory study of the social psychological determinants of regular participation in leisure-time physical activity. Unpublished doctoral dissertation. Griffith University, Brisbane, Australia.

Craike, M.J. (2007). The influence of preference, level of priority and making time on regular participation in leisure-time physical activity. Annals of Leisure Research, 10, 122-145.

Bauman, A., Smith, B., Stoker, L., Bellow, B., \& Booth, M. (1999). Geographical influences upon physical activity participation: Evidence of a 'coastal effect'. Australian and New Zealand Journal of Public Health, 23, 322-324.

Bollen, K. A. (1990). Overall fit covariance structure models: Two types of sample size effects. Psychological Bulletin, 107, 256-259.

Byrne, B. M. (1998). Structural equation modelling with LISREL, PRELIS, and SIMPLIS: Basic concepts, applications, and programming. Mahwah, New Jersey: Lawrence Erlbaum Associates.

Csikszentmihalyi, M. (1975). Beyond boredom and anxiety. San Francisco: Jossey-Bass.

Csikszentmihalyi, M. (1990). Flow: The psychology of optimal experience. New York: Harper Perennial.

Deci, E. L. (1975). Intrinsic Motivation. New York: Plenum Press.

Deci, E. L., \& Ryan, R. M. (1985). Intrinsic motivation and self-determination in human behavior. New York: Plenum Press.

Deci, E. L., \& Ryan, R. M. (1991). A motivational approach to self: Integration in personality. In R. Dienstbier (Ed.), Nebraska symposium on motivation: Perspectives on motivation (pp. 237-288). Lincoln, NE: University of Nebraska

Dillman, D. A. (2000). Mail and internet surveys: The tailored design method (2nd ed.). New York: John Wiley \& Sons.

Efron, B., \& Tibshirani, R. J. (1993). An introduction to the bootstrap. New York: Chapman and Hall.
Enders, C. K., \& Bandalos, D. L. (2001). The relative performance of full information maximum estimation for missing data in structural equation models. Structural Equation Modelling, 8, 430-457.

Gabriele, J.M., Walker, M.S., Gill, D.L., Harber, K.D., Fisher, E.B. (2005). Differentiated roles of social encouragement and social constraint on physical activity behavior. Annals of Behavioral Medicine, 29, 210-215.

Gauvin, L. (1990). An experiential perspective on the motivational features of exercise and lifestyle. $\mathrm{Ca}$ nadian Journal of Sport Science, 15, 51-58.

Giles-Corti, B., \& Donovan, R.J. (2003). Relative influences of individual, social environmental, and physical environmental correlates of walking. American Journal of Public Health, 93, 1583-1589.

Henderson, K.A., Glancy, M., \& Little, S. (1999). Putting the fun into physical activity. Journal of Physical Education, Recreation \& Dance, 70, 43-45.

Hu, L. T., \& Bentler, P. M. (1998). Fit indices in covariance structure modelling: sensitivity to underparameterized model misspecification. Psychological Methods, 3, 424-453.

Hu, L. T., \& Bentler, P. M. (1999). Cutoff criteria for fit indexes in covariance structure analysis: Conventional criteria versus new alternatives. Structural Equation Modelling, 6, 1-55.

Hu, L. T., Bentler, P. M., \& Kano, Y. (1992). Can test statistics in covariance structure analysis be trusted? Psychological Bulletin, 112, 351-362.

Iso-Ahola, S. E. (1980). The social psychology of leisure and recreation. Dubuque, lowa: $\mathrm{Wm} \mathrm{C}$. Brown Company.

Kendzierski, D., \& DeCarlo, K. J. (1991). Physical Activity Enjoyment Scale: Two validation studies Journal of Sport \& Exercise Psychology, 13, 50-64.

Kimiecik, J. C., \& Harris, A. T. (1996). What is enjoyment? A conceptual/definitional analysis with implications for sport and exercise psychology. Journal of Sport and Exercise Psychology, 18, 247-263.

Li, F. (1999). The Exercise Motivation Scale: Its multifaceted structure and construct validity. Journal of Applied Sport Psychology, 11, 97-1 15.

McAuley, E., Duncan, T. E., \& Tammen, V. V. (1989). Psychometric properties of the Intrinsic Motivation Inventory in a competitive sport setting: A confirmatory factor analysis. Research Quarterly for Exercise and Sport, 60, 48-58.

McGinna, A.P., Evensonb, K.R., Herringc, A.H., Huston, S.L. (2007). The relationship between leisure, walking, and transportation activity with the natural environment. Health \& Place, 13, 588-602.

Marsh, H., Balla, J. R., \& McDonald, R. P. (1988). Goodness-of-fit indexes in confirmatory factor analysis: The effect of sample size. Psychological Bulletin, 103, 391-410. 
Martin, J. E., Dubbert, P. M., Katella, A. D., Thompson, J. K., Raczynski, J. R., Lake, M., et al. (1984). Behavioral control of exercise in sedentary adults: Studies 1 through 6. Journal of Consulting and Clinical Psychology, 52, 795-811.

Masters, K. S., \& Lambert, M. J. (1989). The relations between cognitive coping strategies, reasons for running, injury, and performance of marathon runners. Journal of Sport and Exercise Psychology, $11,161-170$

Mullan, E., Markland, D., \& Ingledew, D. K. (1997). A graded conceptualisation of self-determination in the regulation of exercise behavior: Development of a measure using confirmatory factor analytic procedures. Personal Individual Differences, 23, 745-752.

Padgett, V. R., \& Hill, A. K. (1989). Maximizing athletic performance in endurance events: A comparison of cognitive strategies. Journal of Applied Social Psychology, 19, 331-340.

Pelletier, L. G., Fortier, M., Vallerand, R., Tucson, K., Briere, N., \& Blais, M. R. (1995). Toward a new measure of intrinsic motivation, extrinsic motivation, and amotivation in sports: The Sport Motivation Scale (SMS). Journal of Sport and Exercise Psychology, 17, 35-53.

Pennebaker, J. W., \& Lightner, J. M. (1980). Competition of internal and external information in an exercise setting. Journal of Personality and Social Psychology, 39,

Ryan, R. M., \& Deci, E. L. (2000a). Intrinsic and extrinsic motivations: Classic definitions and new directions. Contemporary Educational Psychology, 25, 54-67.

Sallis, J. F., \& Saelens, B. E. (2000). Assessment of physical activity by self-report: Status, limitations, and future directions. Research Quarterly for Exercise and Sport, 7l, 1-14.

Salmon, J., Owen, N., Crawford, D., Bauman, A., \& Sallis, J. F. (2003). Physical activity and sedentary behavior: A population-based study of barriers, enjoyment, and preference. Health Psychology, 22, 178-188.

Schumacker, R. E., \& Lomax, R. G. (1996). A beginner's guide to structural equation modelling. Mahwah, N.J: L.Erlbaum Associates.

Stephenson, J., Bauman, A., Armstrong, T., Smith, B., \& Bellew, B. (2000). The costs of illness attributable to physical inactivity. Canberra: Commonwealth Department of Health and Aged Care.

Tabachnick, B. G., \& Fidell, L. S. (2007). Using multivariate statistics (5th ed.). Boston, Mass: Allyn and Bacon.

Thogersen-Ntoumani, C., \& Ntoumanis, N. (2006). The role of self-determined motivation in the understanding of exercise-related behaviours, cognitions and physical self-evaluations. Journal of Sports Sciences, 24, 393-404.

Tsai, E. H. (2002). A cross-cultural study of psychosocial determinants of sedentary and active leisure behaviours: Australia and Hong Kong. Unpublished Doctor of Philosophy, Griffith University, Brisbane.

Tsai, E. H. (2005). A cross-cultural study of the influence of perceived positive outcomes on participation in regular active recreation: Hong Kong and Australian University students. Leisure Sciences, 27, 385-404.

U.S Department of Health and Human Services (1996). Physical activity and health: A report of the surgeon general. Boston: Jones and Bartlett.

Wankel, L.M. (1985). Personal and situational factors affecting exercise involvement: The importance of enjoyment. Research Quarterly for Exercise and Sport, 56, 275-282.

Wankel, L. M. (1993). The importance of enjoyment to adherence and psychological benefits from physical activity. International Journal of Sport Psychology, 24, 151-169.

Wilson, P. M., Rogers, W. M., \& Fraser, S. N. (2002a). Cross-validation of the revised motivation for physical activity measure in active women. Research Quarterly for Exercise and Sport, 73, 471-477.

Wilson, P. M., Rodgers, W. M., \& Fraser, S. N. (2002b). Examining the psychometric properties of the Behavioral Regulation in Exercise Questionnaire. Measurement in Physical Education and Exercise Science, 6, 1-21.

MELINDA J. CRAIKE, PhD
Deakin University, Australia

RAYMOND HIBBINS, PhD

Griffith University, Australia

GRAHAM CUSKELLY, PhD

Gold Coast Campus, Griffith University, Australia

Address for correspondence:
MELINDA J. CRAIKE, PhD
Deakin University
221 Burwood Hwy
Burwood, Vic, 3125, Australia
Phone: +61 398954034
Fax: +61398953575
Email Address:
Melinda.Craike@deakin.edu.au 